\title{
Research and analysis of coupling coordination degree between tourism industry and regional economy in Wuhu City
}

\author{
Li Guanghong ${ }^{1}, \mathrm{Hu}$ Yuan $^{1}$ \\ ${ }^{1}$ College of Tourism and Landscape Architecture, Guilin University of Technology, Guilin Guangxi 541000, China
}

\begin{abstract}
Taking Wuhu City of Anhui Province as an example, this paper constructs two evaluation index systems of tourism industry and regional economic development respectively, and studies the coupling coordination situation and influencing factors of Wuhu City from 2015 to 2019 by using the coupling coordination degree model. The research shows that the comprehensive development level of Wuhu tourism industry and regional economy system has been steadily improved year by year in the past five years. Coupling degree $\mathrm{C}$ showed an up-down trend, but was generally at a high level. The comprehensive development level $\mathrm{T}$ of the two systems is also in an increasing trend. By 2019, the coupling coordination degree of the tourism-industry system in Wuhu has been upgraded from good coordination to high quality coordination. In the future development process, Wuhu City should continue to promote GDP growth on the basis of the current good development situation, and realize the win-win situation between tourism and regional economic development.
\end{abstract}

\section{Introduction}

Located on the south bank of the lower reaches of the Yangtze River, Wuhu has convenient transportation and abundant products. Besides rich natural resources, it also has rich historical and cultural resources. In 2008, Wuhu Special Park was officially opened, and in 2013, it was rated as a national 5A tourist scenic spot. The scenic spot attracted tourists and special fans from all over the country with its excellent services and products. Its establishment injected strong impetus into the tourism development of Wuhu City, and made positive contributions to the building of Wuhu tourism industry highland. In 2019, the total tourism revenue of Wuhu was 87.287 billion yuan, up $13.7 \%$ year on year, accounting for $24.12 \%$ of the regional GDP, 1.94 percentage points more than in 2018. Through a large number of literature review and data research, it is shown that the development of tourism industry and regional economic development are interactive. For example, Tugcu ${ }^{[1]}$, a foreign scholar, studied the causal relationship between tourism and regional economic growth in Mediterranean countries and found that tourism contributes greatly to economic growth. $\mathrm{Yu} \mathrm{Jie}{ }^{[2]}$, a domestic scholar, conducted a quantitative study on the coordination between the tourism industry and the regional economy in 17 prefecture-level cities in Shandong Province through the coupling and coordinated development model, and concluded that the two are mutually influenced and restricted.

In summary, the research on the relationship between the tourism industry and the regional economy using the coupling coordination degree model mainly focuses on the provinces, and there are few studies on the municipalities. Therefore, this article takes Wuhu City as an example. Based on the existing evaluation index system, an evaluation index system for Wuhu's tourism industry and regional economic development is constructed, and the coupling coordination degree model is used to analyze the relationship between the two. The development of the tourism industry puts forward feasibility suggestions in order to make up for the gaps in Wuhu's tourism economic research academically.

\section{Overview of the study area}

Wuhu is an economic, cultural, transportation, and political sub-center of Anhui Province. It is also a key open city along the river approved by The State Council. In 2001, it was rated as a National Excellent Tourist City. The city scale and economic development level are next to the provincial capital city of Hefei. Following the regional adjustment of Anhui Province, the development of Wuhu City has further accelerated, and the economic aggregate and per capita have reached the level of Jiangsu. The unique development strategic position and superior location advantage are beneficial to the economic development of Wuhu area. In addition, the city is rich in tourism resources. By 2019, the city has 10 scenic spots above the $3 \mathrm{~A}$ level. The historical and cultural resources are also very rich, which is conducive to the development of the local tourism industry.

${ }^{1}$ Corresponding author: 2240002785@qq.com 


\section{Research methods}

\subsection{Indicator system}

This study mainly involves two systems of tourism industry and regional economic development. Based on the principles of scientific and operable index selection, on the basis of the existing evaluation index system, the evaluation index system of Wuhu tourism industry and the evaluation index system of regional economic development are respectively constructed. The specific indicators and weights are shown in Table 1. All data are from the Statistical Yearbook of Wuhu City from 2015 to 2019.

Table1. Index system and weight of coupling coordination degree between tourism industry and regional economy

\begin{tabular}{ccc}
\hline System & The evaluation index & The weight \\
\hline \multirow{2}{*}{$\begin{array}{c}\text { The tourism } \\
\text { industry }\end{array}$} & Domestic tourism revenue (100 million yuan) & 0.1539 \\
& Dorned foreign exchange from tourism (USD 10,000) & 0.1763 \\
& Inbound Tourist Number (person) & 0.1480 \\
Number of star hotels (home) & 0.1686 \\
Regional & Travel Agency (home) & 0.1854 \\
economic & GDP (100 million yuan) & 0.1678 \\
development & Output value of the tertiary industry (100 million yuan) & 0.1633 \\
& Financial revenue (100 million yuan) & 0.1838 \\
& Per capita disposable income (yuan) & 0.1445 \\
& Total retail sales of consumer goods (100 million yuan) & 0.1637 \\
& Traffic passenger volume (ten thousand) & 0.1589 \\
\hline
\end{tabular}

\subsection{Construction of coupling coordination degree model}

Coupling refers to the interaction and mutual influence of two or more systems or elements ${ }^{[3]}$. The degree of coupling indicates the degree of influence between systems or elements. The more connections between systems, the stronger the coupling. In order to study the relationship between the tourism industry and regional economic development in Wuhu City, this paper decided to adopt the dual system coupling model of tourism industry and regional economy ${ }^{[4]}$, the formula is as follows:

$$
\begin{gathered}
\mathrm{C}=\left\{\frac{\mathrm{X} \cdot \mathrm{Y}}{\left[\frac{\mathrm{X}+\mathrm{Y}}{2}\right]^{2}}\right\}^{\mathrm{k}}, \mathrm{T}=\alpha X+\beta Y, \quad \mathrm{D}=\sqrt{\mathrm{C} \cdot \mathrm{T}} \\
\mathrm{X}=\sum_{\mathrm{i}=1}^{\mathrm{m}} \mathrm{a}_{\mathrm{i}} \mathrm{X}_{\mathrm{i}} \quad \mathrm{Y}=\sum_{\mathrm{j}=1}^{\mathrm{n}} \mathrm{b}_{\mathrm{j}} \mathrm{y}_{\mathrm{j}}
\end{gathered}
$$

In formula (1), $\mathrm{C}$ represents the degree of coordination between the two systems, $\mathrm{k}$ is the coordination coefficient $(\mathrm{k} \geq 2)$, where $\mathrm{k}=2 ; \mathrm{T}$ represents the comprehensive evaluation index of the two systems, and $\alpha$ and $\beta$ are undetermined coefficients. The mutual coordination between systems is asymmetrical. Regional economic development is the result of multiple influencing factors including the tourism industry. Therefore, $\alpha=0.6$ and $\beta=0.4$ are generally assigned ${ }^{[5]}$; D represents the degree of coupling and coordination.

In formula (2), $\mathrm{X}$ represents the comprehensive evaluation index of the tourism industry, $a_{i}$ represents the weight of the i-th indicator in the tourism industry system, $x_{i}$ represents 6 indicators including domestic tourism income representing the development of the tourism industry; $\mathrm{Y}$ represents the comprehensive evaluation index of the level of regional economic development, $b_{j}$ represents the weight of the $\mathrm{j}$-th indicator in the regional economic development system, and $y_{j}$ represents 6 indicators such as GDP representing regional economic development, all of which are infinite steel values.

In order to reflect the degree of coupling and coordination between the tourism industry system and the regional economic development system, this paper refers to the research results of Liao Zhongbin ${ }^{[6]}$ and divides the degree of coupling and coordination into the following 10 levels, as shown in Table 2. 
Table2. Classification standard of coupling coordination degree

\begin{tabular}{cccccc}
\hline $\begin{array}{c}\text { Serial } \\
\text { number }\end{array}$ & Coordination & Coordination level & $\begin{array}{c}\text { Serial } \\
\text { number }\end{array}$ & Coordination & Coordination level \\
\hline 1 & $0.00-0.09$ & Extreme imbalance & 6 & $0.50-0.59$ & Barely tuned \\
2 & $0.10-0.19$ & Severe imbalance & 7 & $0.60-0.69$ & Primary coordination \\
3 & $0.20-0.29$ & Moderate Disorder & 8 & $0.70-0.79$ & $\begin{array}{c}\text { Intermediate } \\
\text { coordination }\end{array}$ \\
4 & $0.30-0.39$ & Mild disorder & 9 & $0.80-0.89$ & Well coordinated \\
5 & $0.40-0.49$ & $\begin{array}{c}\text { On the verge of } \\
\text { maladjustment }\end{array}$ & 10 & $0.90-1.00$ & Quality coordination \\
\hline
\end{tabular}

\section{Analysis of coordination level between tourism industry and regional economy}

Table3. Values and grades of coupling coordination degree between tourism industry and regional economy in Wuhu City

\begin{tabular}{|c|c|c|c|c|c|c|c|}
\hline Year & $\mathrm{X}$ & $\mathrm{Y}$ & $\mathrm{C}$ & $\mathrm{T}$ & $\mathrm{D}$ & Coupling coordination level & Contrast type \\
\hline 2015 & 0.6357 & 0.7164 & 0.9929 & 0.6680 & 0.8144 & Well coordinated & $\begin{array}{c}\text { Tourism industry is relatively } \\
\text { backward type }\end{array}$ \\
\hline 2016 & 0.6709 & 0.7547 & 0.9931 & 0.7044 & 0.8364 & Well coordinated & $\begin{array}{c}\text { Tourism industry is relatively } \\
\text { backward type }\end{array}$ \\
\hline 2017 & 0.7853 & 0.7749 & 0.9999 & 0.7811 & 0.8838 & Well coordinated & $\begin{array}{l}\text { Regional economy lags } \\
\text { behind relatively }\end{array}$ \\
\hline 2018 & 0.8750 & 0.8544 & 0.9997 & 0.8668 & 0.9309 & Quality coordination & $\begin{array}{l}\text { Regional economy lags } \\
\text { behind relatively }\end{array}$ \\
\hline 2019 & 0.9768 & 0.9035 & 0.9970 & 0.9475 & 0.9719 & Quality coordination & $\begin{array}{l}\text { Regional economy lags } \\
\text { behind relatively }\end{array}$ \\
\hline
\end{tabular}

According to the above table:

(1) During 2015-2019, the comprehensive evaluation index $\mathrm{X}$ of Wuhu's tourism industry development level increased from 0.6357 to

0.9768, a large increase, indicating that the comprehensive development level of Wuhu's tourism industry was gradually improving; the comprehensive evaluation index $\mathrm{Y}$ of regional economic development level increased from 0.7164 increased to 0.9035 , a steady increase year by year, indicating that the overall development of the regional economy in Wuhu City is better.

(2) From the perspective of the coupling degree C between Wuhu's tourism industry and the regional economy, it was on an upward trend from 2015 to 2017 , reaching a high value of 0.9999 in 2017, and a low downward trend in the next two years, but the overall level is still greater than 0.99 , which shows that the interaction and influence between the tourism industry and the regional economy are in a benign state and should continue to be maintained.

(3) From the perspective of the comprehensive development level $\mathrm{T}$ of the two systems of tourism industry and regional economy in Wuhu City, it has

According to the above methods and formulas, the development level of the tourism industry and regional economy of Wuhu City from 2015 to 2019 is calculated, and the coupling coordination model is used to evaluate the development level. The results are shown in Table 3. 
card for attracting foreign investment and many tourists. Wuhu must strengthen brand building and make arrangements for industrial transformation and upgrading. Relying on the existing resources, cultivate the "red, blue and green" development concept, that is, the integrated development of red tourism resources, green tourism resources and high-tech tourism industry, tell the story of Wuhu to tourists, and strive to enhance the image of Wuhu tourist attractions and cities, and attract the eyes of the world; (2) the number of star-rated hotels in Wuhu City has not increased but decreased in the past five years. By 2019, there are only 28. Therefore, Wuhu City should expand the construction of star-rated hotels, improve the service level and quality of the hotel industry, and further improve the city quality; (3) enhancing the connection with tourism cities in the Yangtze River Delta, Nanjing Metropolitan Area and other regions, realizing resource sharing, information exchange, and guest interaction, so that the local tourism industry can achieve sustainable development; (4) the development of tourism is inseparable from the correct leadership of tourism bureaus and tourism associations, as well as the service and cooperation of tour guide staff. Therefore, improving the level of tourism services and regulating the order of the tourism market are essential to promote the orderly and healthy development of the tourism industry.

At the regional economic level: (1) the government needs to continuously improve the city's infrastructure, optimize the urban transportation system, improve the accessibility of roads and railways, enhance the air transportation capacity, and increase the accessibility of the city; (2) increase investment in science and technology, promote industrial upgrading, improve production efficiency, and achieve coordinated regional economic development; (3) strengthen the construction of people's livelihood projects, improve people's life satisfaction and happiness; (4) support the development of the tertiary industry, provide it with strong policy support and create a better industry environment, so that it can give full play to the foreign exchange and tax revenue generation. Ability to inject fresh vitality into the development of the national economy.

\section{Conclusion}

Taking Wuhu City as an example, this paper conducts a quantitative analysis of the coupling and coordination relationship between the local tourism industry and the regional economy, and concludes that the interaction and influence between the two systems of the city are in a benign state. In recent years, Wuhu City has vigorously developed global tourism and has achieved remarkable results in integrating into the integrated development of the Yangtze River Delta. Therefore, Wuhu City should seize the development opportunities of the times, make good use of its own superior conditions, continue to promote the steady growth of GDP based on the current good development trend, and achieve a win-win situation for tourism and regional economic development.

\section{Reference}

1. Tugcu C T. Tourism and economic growth nexus revisited: A panel causality analysis for the case of the Mediterranean Region[J]. Tourism Management, 2014.

2. Yu Jie. Evaluation and optimization of coordination degree between tourism industry and regional economy in Shandong Province[J].China Population, Resources and Environment, 2014, 24(4):163-168. DOI:10.3969/j.issn.1002- 2104.2014.04.022.

3. Ding Hongmei. Empirical Analysis of Coupling Coordination Degree between Tourism Industry and Regional Economic Development_-Taking Huangshan City as an Example [J]. Business Economics and Management, 2013(07): 81-87.

4. Wang Liguo, Jiang Rui. Research on the Coupling Degree of City Tourism Industry and Regional Economic Coupling_-Taking Nanchang City, Jiangxi Province as an Example [J]. Journal of Agricultural and Forestry Economic Management, 2017, 16(6): 783-788. DOI: 10.16195 /j.cnki.cn361328/f.2017.06.12.

5. Liao Zhongbin. Quantitative Evaluation and Classification System of the Coordinated Development of Environment and Economy: Taking the Urban Agglomeration of the Pearl River Delta as an Example [J]. Tropical Geography, 1999(02): 76-82.

6. Tang Rui, Feng Xuegang. Research on the dynamic relationship between China's tourism economy and new urbanization $[\mathrm{J}]$. Journal of Agricultural and Forestry Economics and Management, 2016(1): 106114. 